\title{
ВЕГЕТАТИВНАЯ СФЕРА ЮНОШЕЙ 15-18 ЛЕТ С ПОГРАНИЧНЫМИ НАРУШЕНИЯМИ В СПОКОЙНОМ СОСТОЯНИИ И ПРИ РАЗЛИЧНЫХ ЭМОЦИОГЕННЫХ ВОЗДЕЙСТВИЯХ
}

${ }^{1}$ Казымов А. Г., ${ }^{1}$ Мамедов А.М., ${ }^{1}$ Алиева Д.М., ${ }^{2}$ Гасанов Х.И.

${ }^{1}$ Кафедра нормальной физиологии, Азербайджанский Медицинский Университет ${ }^{2}$ Республиканская клиническая больница им. акад. Мир-Касимова

Ключевые слова: юношеский возраст, вегетативная нервная система, эмоциональное состояние, вегетативные пробы.

Невротические расстройства являются одной из наиболее актуальных проблем детского и подросткового возраста $[9,10,12,17]$. Здоровый человек реагирует избирательно, имеет так называемый психофизиологический паттерн, лежащий в основе его поведения. Больной мобилизует все вегетативные системы диффузно. В основе этого лежит особое состояние мозгового гомеостаза: наличие диффузной генерализованной активации неспецифических мозговых систем как в восходящем (биологические мозговые ритмы), так и в нисходящем направлении - вегетативные ответы: ЧСС, частота дыхания (ЧД), кожногальванический реакции (КГР), артериального давления (АД) и др. [13].

\section{Клиническим}

выражением эмоционально-поведенческих реакций человека являются их вегетативные сопровождения: изменения цвета лица, сердечного ритма, дыхания, озноб, колебания АД и т.д. Это дает возможность говорить о существовании психовегетативного единства, обусловленного как анатомо-физиологическими, так и функционально-биологическими данными, присущего как здоровому человеку, так и больному (психовегетативный синдром).

В ряде работ [1,14] у детей 7-8 лет с неврозами выявлены сильные межполушарные и межзональные корреляционные связи в передних областях мозга. У больных с двигательными расстройствами отмечены более слабые связи в этих областях и между затылочными отделами мозга. Тем не менее, следует отметить, что онтогенетическому аспекту проблемы изучения вегетативных показателей при различных функциональных состояниях невротиков различного возраста не уделялось должного внимания.
В настоящей работе поставлена основная цель изучить состояние синхронизирующих и десинхронизирующих систем, вегетативной сферы при различных функциональных состояниях мозга юношей (15-18 лет) с невротическими нарушениями.

Методы и материалы исследования. Нами проведены исследования у 48 практически здоровых юношей и 48 юношей 15 18 лет с невротическими нарушениями. Они подразделялись на четыре возрастные группы: $15,16,17,18$ лет (в каждой возрастной группе по 12 юношей.) Полиграфические исследования включали одновременную регистрацию на 8 16- канальном электроэнцефалографах фирмы «Медикор» и вегетативных показателей: электрокардиограммы (ЭКГ), пневмограммы (ПНГ), плетизмограммы (ПГ) и КГР при различных функциональных состояниях: спокойном, напряженном, отрицательно- и положительно- эмоциональном состояниях.

Спокойное состояние испытуемых записывалось после предварительной 15-20тиминутной адаптации в затемненной камере, при расслабленном бодрствовании, полулёжа, с закрытыми глазами. Напряженное состояние создавали моделированием умственной нагрузки - счет в уме (решение арифметических задач различной степени сложности), или составление слов (например, пять слов по пять букв). Моделирование отрицательноэмоционального состояния осуществлялось посредством словесного порицания. Положительно - эмоциональное состояние моделировалось посредством словесного одобрения.

По ведущему клиническому синдрому психоневрологические нарушения характеризовались выраженным беспокойством 
за состоянием здоровья, акцентом на соматические жалобы, эмоциональноаффективными расстройствами в виде постоянного состояния тревожности.

\section{Регистрацию}

пневмограммы осуществляли с помощью датчика фирмы "Nihon Koden", который укрепляли у испытуемых на коже у носового прохода. Постоянная времени 01/с при фильтрах 15 Гц. ЧД подсчитывалась также как ЧСС.

Плетизмограмма регистрировалась при помощи датчика фирмы "Nihon Koden" с указательного пальца левой руки. Постоянная времени 0,3 с при фильтрах 30 Гц. Измерялась амплитуда плетизмаграфической кривой, которая выражалась в единицах относительного состояния спокойного бодрствования.

КГР регистрировалась по методу Тарханова с тыльно-ладонной поверхности кисти с помощью свинцовых плоских пластинок площадью 3-4 $\mathrm{cm}^{2}$ и оценивалась по пятибалльной шкале с последующим подсчетом в относительных единицах постоянной времени 0,3 с при фильтрах 30 Гц [11].

Исследование состояния вегетативной нервной системы заключалось в изучении вегетативной реактивности (по глазосердечной, синокаротидной и солярной пробам). Вегетативное обеспечение физической деятельности исследовались орто- и клиностатических пробами.

Во всех пробах измеряли также систолическое, диастолическое кровяное давление.

Результаты исследования. Исследование вегетативной реактивности (рис. 1) показало, что у 15-тилетних юношей при проведении пробы Ашнера частота пульса урежается

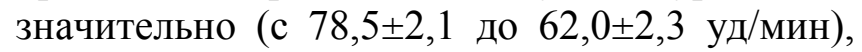
выражено урежение при солярной пробе до

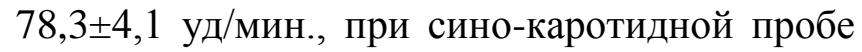
не изменяется (78,3 $\pm 4,1$ удар/мин), приближается к исходному уровню. Аналогичная динамика выявляется также у юношей в 16-ти летнем возрасте. При этом, если при пробе Ашнера обнаруживается некоторое снижение частоты пульса $(76,1 \pm 2,7$ до $67,0 \pm 2,3$ уд/мин), то в остальных пробах этот показатель динамику не прослеживает. При давлении на рефлекторные зоны у подростков 17-ти лет, как видно из рис. 1, частота пульса имеет незначительные отклонения от фоновых показателей, от $70,0 \pm 2,2$ до $64,0 \pm 2,1 ;$ у подростков 18-ти лет частота пульса при глазо-сердечной пробе урежается от $68 \pm 1,5$ до 56,0 2,7 уд/мин. Таким образом, исследование вегетативной реактивности указывает на понижение или же извращение реактивности у юношей с невротическими расстройствами во всех возрастных группах и свидетельствует о повышении симпатических влияний на вегетативную реактивность, возникающих в ответ на раздражения рефлекторных зон.

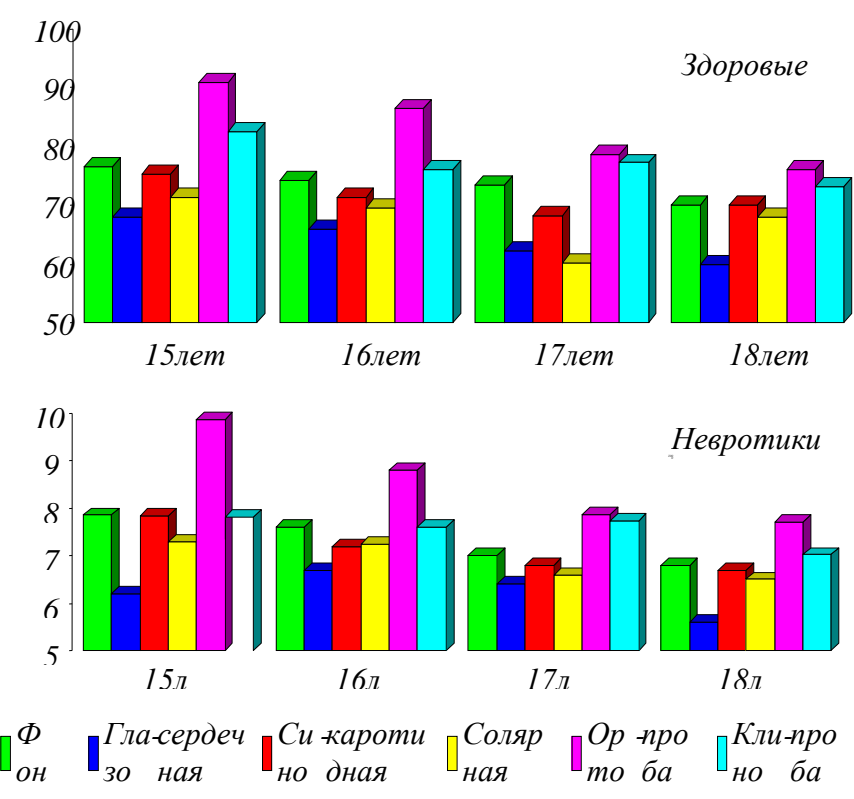

Рис. 1. Показатели вегетативной реактивности и ортоклиностатической пробы у юношей.

C целью определения вегетативного обеспечения психической деятельности у больных с невротическими нарушениями исследовалась динамика вегетативных показателей при различных функциональных состояниях. В группе подростков 15-ти лет

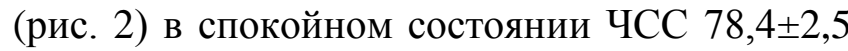

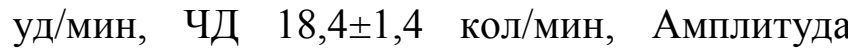

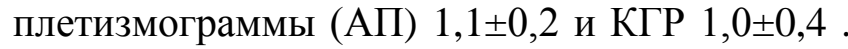
При моделировании умственной деятельности

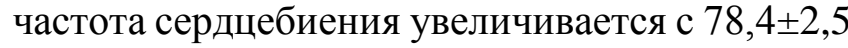
до $88,0 \pm 2,6$ уд/мин $(\mathrm{P}<0,01)$, частота дыхания значительно увеличивается от $18,4 \pm 1,4$ до $23,0 \pm 1,1 \quad(\mathrm{P}<0,05)$, что носит достоверный 
характер. Амплитуда плетизмограммы снижается с $1,1 \pm 0,2$ до $0,7 \pm 0,08$, а

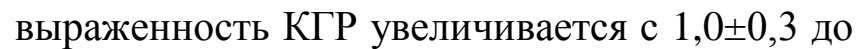
$1,6 \pm 0,3$.
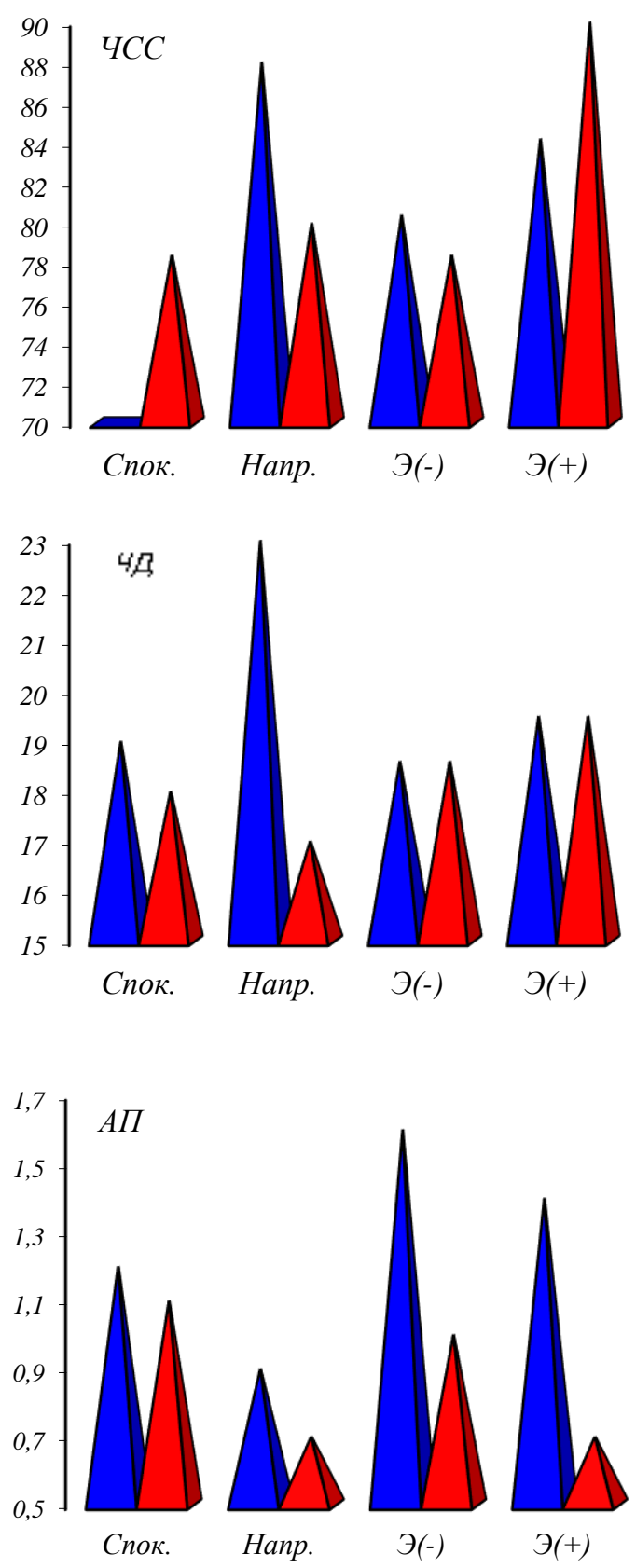

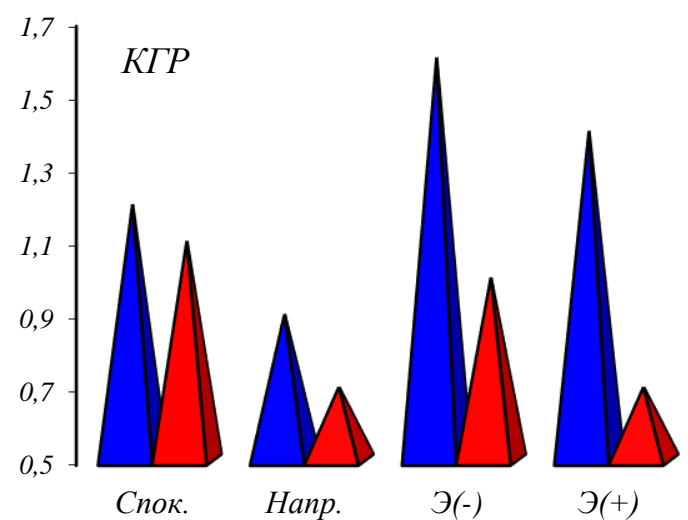

Здоровые

Невротики

Рис. 3. Вегетативные показатели в различных состояниях у юношей 16 лет. Обозначения на рис. 2.

В то же время у здоровых в этом возрасте достоверные сдвиги в частоте сердцебиения и дыхания при изменениях функционального состояния не наблюдались. При моделировании отрицательно-эмоциональных состояний показатели ЧСС учащаются с $80,4 \pm 4,5$ до $92,0 \pm 2,2 \quad(\mathrm{P}<0,05), \quad$ показатели ЧД имеют тенденцию к снижению до исходных величин (с $17,6 \pm 1,6$ до $15,6 \pm 2,6)$. Амплитуда плетизмограммы увеличивается в динамике с $1,4 \pm 0,2$ до $1,6 \pm 0,1$, КГР также как и у 15 и 16тилетних при отритцательно-эмоциональных нагрузках, по сравнению с расслабленным бодрствованием, имеет более высокие значения, соответственно при отрицательноэмоциональном состоянии с $1,6 \pm 0,1$ до $2,1 \pm 0,9$ $(\mathrm{P}<0,05) ;$ при положительно-эмоциональном

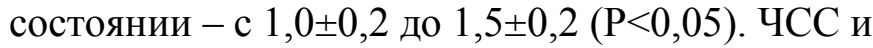
ЧД увеличивались с $83,1 \pm 4,5$ до $95,0 \pm 2,3$ $(\mathrm{P}<0,05)$ и с $18,2 \pm 0,5$ до $24,2 \pm 0,4(\mathrm{P}<0,001)$.

У юношей с невротическими расстройствами 17-ти лет (рис 4.) частота сердечных сокращений при спокойном состоянии резко повышается с $72,1 \pm 2,1$ до $92,0 \pm 4,4(\mathrm{P}<0,01)$. 

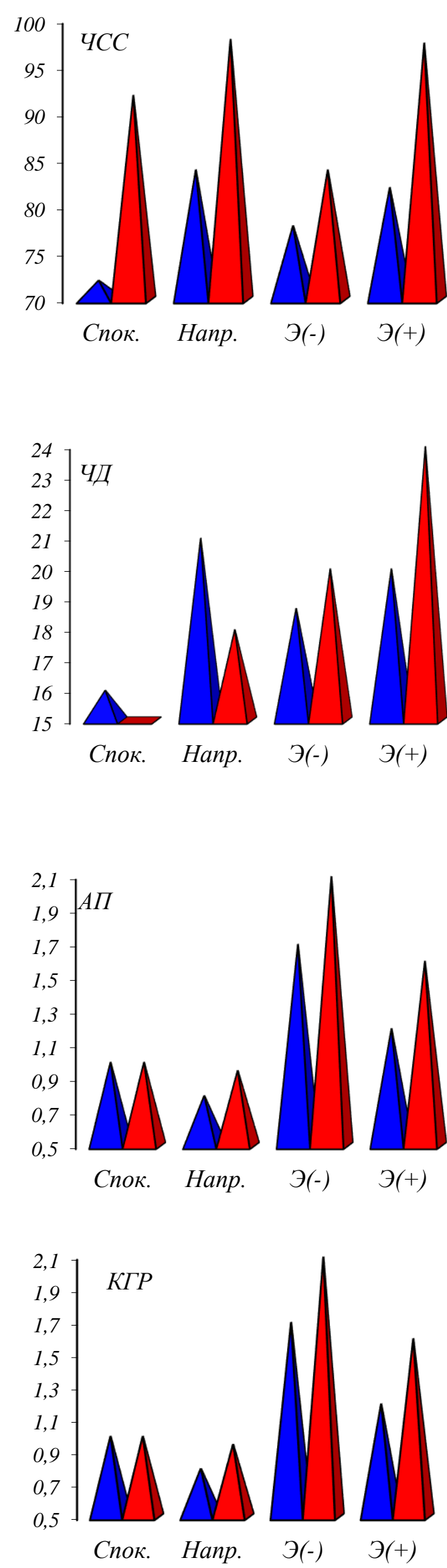

Рис. 4. Вегетативные показатели в различных состояниях у юношей 17 лет. Обозначения на рис. 2.

Наблюдается увеличение ЧСС, отмеченное в напряженном состоянии (с $84,0 \pm 2,7$ до $98,0 \pm 3,2(\mathrm{P}<0,01)$, в ЧД отмечено снижение с $21,0 \pm 2,0$ до $18,0 \pm 0,9$. В снижении амплитуды плетизмограммы и выраженности КГР достоверных изменений не наблюдалось. При отрицательно-эмоциональных состояниях отмечается увеличение ЧСС с $78 \pm 3,4$ до $84 \pm 2,8$ уд/мин, ЧД увеличивается с $18,7 \pm 2,1$ до $20 \pm 2,1$, кол/мин, изменения АП в динамике с $1,7 \pm 0,1$ до $2,1 \pm 0,1(\mathrm{P}<0,01)$, КГР от $1,3 \pm 0,1$ до $1,8 \pm 0,8 \quad(\mathrm{P}<0,05)$. При положительноэмоциональных состояниях ЧСС меняется с $82,1 \pm 2,5$ до 97,6 $\pm 2,4$ уд/мин. $(\mathrm{P}<0,05)$, а ЧД от $20 \pm 0,5$ до $24 \pm 0,7 \quad(\mathrm{P}<0,001)$. Амплитуда плетизмограммы - от $1,2 \pm 0,1$ до $1,6 \pm 0,1$ $(\mathrm{P}<0,01)$, а кожно-гальваническая реакция - от $1,2 \pm 0,2$ до $2,1 \pm 0,9(\mathrm{P}<0,05)$.
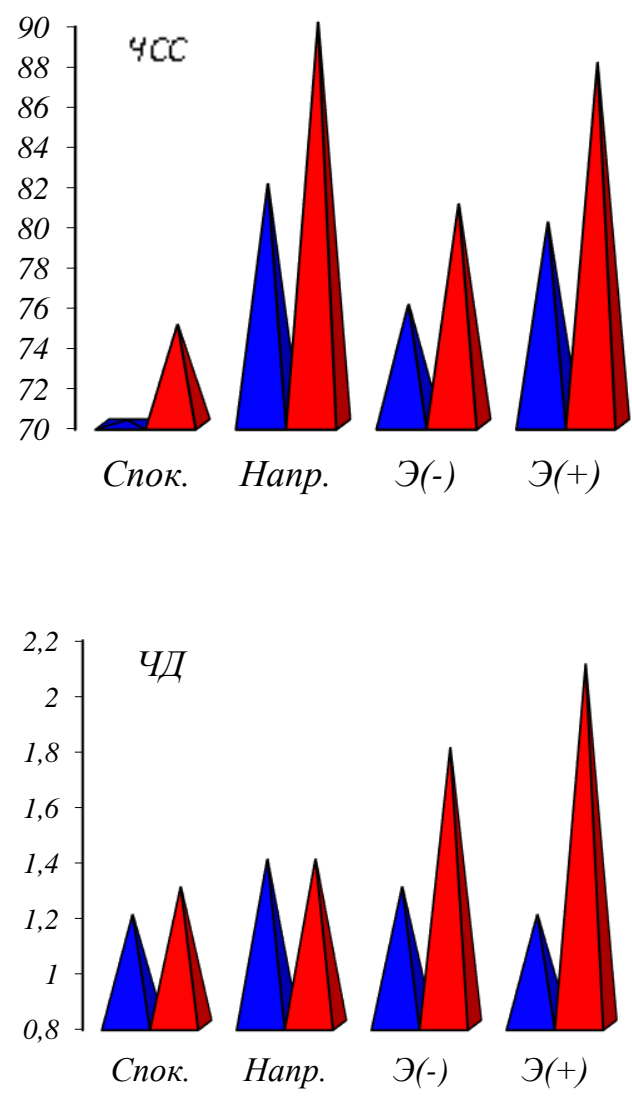
Здоровые
$\square$ Невротики 

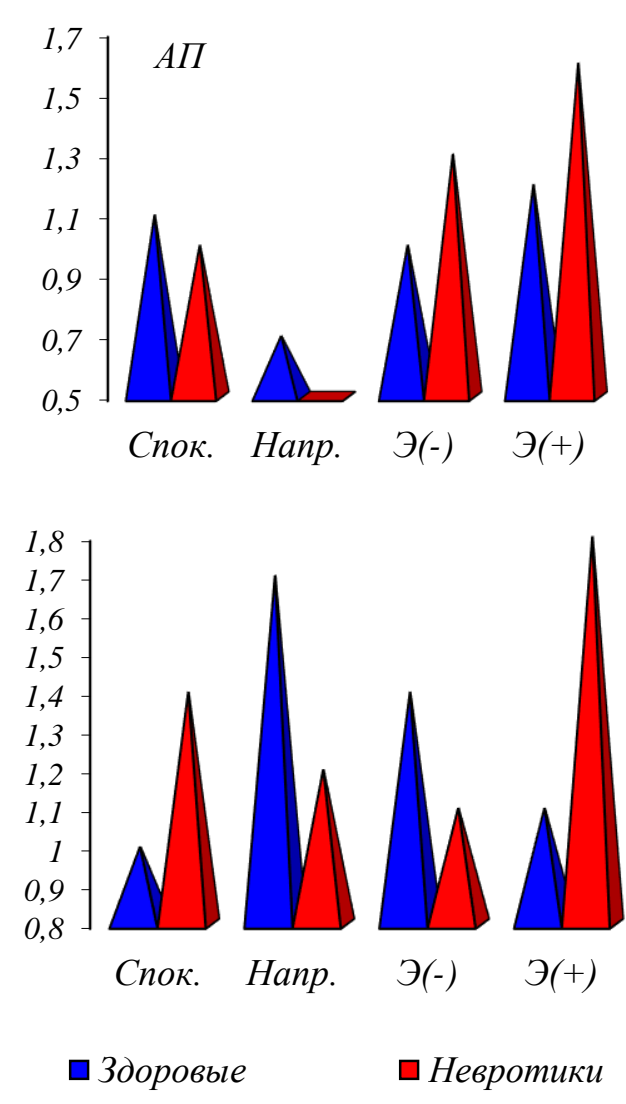

Рис.5 Вегетативные показатели в различных состояниях у юношей 18 лет. Обозначения на рис. 1.

Как видно из рис. 5, у юношей с невротическими расстройствами 18-ти лет, в сравнении со здоровыми, в спокойном состоянии наблюдались достоверные изменения ЧСС, при моделировании состояния напряжения в этой же группе ЧСС с $82,0 \pm 2,1$ уд/мин.

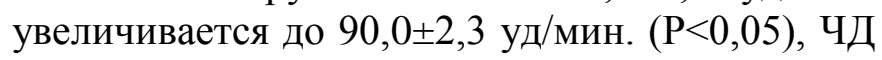

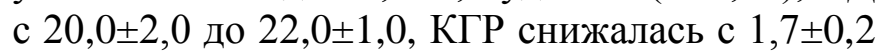
до $1,2 \pm 0,1 \quad(\mathrm{P}<0,05)$. При отрицательноэмоциональных нагрузках отмечается учащение частоты сердцебиения, соответственно с

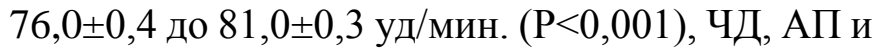
КГР изменялись не достоверно. При положительно-эмоциональном состоянии увеличилось ЧСС ( от $80,1 \pm 2,3$ до $88,0 \pm 2,4$ уд/мин. $(\mathrm{P}<0,05))$, частота дыхания у больных данной возрастной группы не изменена. АП увеличивалась с 1,2 $\pm 0,1$ до $1,6 \pm 0,5(\mathrm{P}<0,05)$, выраженность КГР - от $1,1 \pm 0,1$ до $1,8 \pm 0,3$, $(\mathrm{P}<0,05)$. Если в группе здоровых юношей 18 -ти лет амплитуда плетизмограммы при функциональных нагрузках изменяется, то у больных в напряженном состоянии отмечается снижение этого показателя с $1,0 \pm 0,4$ до $0,5 \pm 0,3$, а при положительно-эмоциональном состоянии

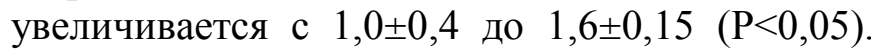
Достоверные изменения КГР наблюдаются лишь при моделировании положительноэмоционального состояния. При этом

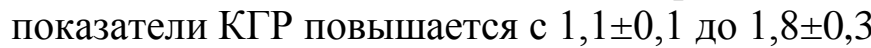
$(\mathrm{P}<0,05)$

На рис.1, представлены результаты анализа орто-клиностатической пробы при неврозах подросткового и юношеского возраста. Следует отметить, что у больных 15 лет ЧСС

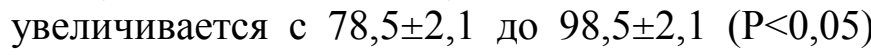
также, как и в группе здоровых, при вертикальном положении тела и возвращается к исходному уровню при горизонтальном. Однако, в отличие от здоровых, во всех возрастных группах учащение пульса при ортопробе превышает 10-12 уд/мин и указывает на избыточность эрготропных влияний вегетативного обеспечения физической деятельности.

Таким образом, у юношей с невротическими расстройствами во всех возрастных группах наблюдается усиление эрготропных сдвигов в вегетативной нервной системе при психической и физической деятельности, которая в отличие от здоровых имеет избыточный характер. При этом более выраженные изменения наблюдаются у больных 16-17 лет.

Обсуждение полученных данных. Вегетативные расстройства занимают значительное место в клинической картине неврозов и в настоящее время накопилось достаточно фактического материала, позволяющего говорить об облигатности вегетативных нарушений при неврозах $[8,16,18]$. Исследование вегетативной сферы юношей с неврозом, по сравнению со здоровыми, выявляет увеличение вегетативного тонуса, при этом вегетативное обеспечение психической деятельности избыточно [3]. Вегетативные нарушения редко выступают в роли самостоятельного заболевания, как правило, они являются вторичными, развиваясь на фоне разного рода психических, соматических, неврологических заболеваний. В одних случаях они играют существенную роль в патогенезе 
заболевания, в других возникают вторично, но оказывают влияние на его течение [14].

Известно, что в неспецифических системах мозга в пределах лимбикоретикулярного комплекса локализуются центральные и надсегментарные аппараты вегетативной нервной системы $[4,5,6,7]$, состоящие из активирующих или эрготропных и тормозных или трофотропных механизмов. При этом в состоянии расслабленного бодрствования складывается сбалансированная взаимосвязь между этими звеньями, которая по определению отражается в понятии вегетативного тонуса организма. Вегетативный баланс на периферии определяется равновесием симпатических и парасимпатических механизмов.

При изменениях функционального состояния прослеживалась тенденция к увеличению частоты сердцебиения, дыхания, снижению амплитуды плетизмограммы и повышению выраженности КГР. Аналогическая динамика вегетативных показателей, отражающая уровень активности центральной нервной системы при переходе от состояния покоя к активной деятельности, было отмечена и другими исследователями [2,11].

Ряд авторов особо выделяют изменение реактивности вегетативных систем, определяющее значительное снижение адаптивных возможностей организма, а также нарушения целостной, сопряженной функции различных компонентов вегетативных систем и тотальность вегетативных дисфункций. Фазические сдвиги зависят от степени напряжения исходного тонического уровня вегетативных показателей [6,15]. Чем больше тонические напряжения, тем слабее выраженность фазических сдвигов. Это взаимоотношение впервые было описано Walter W.G. [19] и сформулировано как «Закон исходного уровня». В данном случае отсутствие динамики вегетативных показателей может быть объяснено действием этого закона, что в свою очередь подтверждает правильность его основных положений.

Таким образом, выявлено, что возрастные характеристики развития и динамика вегетативных функций являются объективными индивидуальнотипологическими показателями и различаются по кардио-респираторным параметрам функций и изменений эмоциональновегетативной реактивности. В условиях физиологического покоя кардиореспираторные и эмоционально-вегетативные показатели у 15-16-тилетних юношей обнаруживают высокую вариабельность абсолютных значений функций (ЧСС, ЧДД, АД).

\section{СПИСОК ЛИТЕРАТУРЫ}

1. Адигезалова В.А., Асадова М.С. Особенности пространственно-временной организации ЭЭГ при различных функциональных состояниях у детей 7-8 лет больных неврозом. / Матер. II съезда общества физиологов Азербайджана. Баку, 1999, с 26-27. 2. Аллахвердиев А.Р. Онтогенетические особенности функционирования неспецифических систем мозга детей в норме и при неврозах: Автореф. дис. ... докт. мед. наук. M., 1988, 38 c.

3. Алекперова Х.М. Влияние функционального биоуправления на состояние психовегетативной сферы у юношей с неврозами / Матер. II съезда общества физиологов Азербайджана. Баку, 1999, с. 2829.

4. Вейн А.М. Лекции по неврологии неспецифических систем мозга. М., 1974, 119 с.

5. Вейн А.М., Колосова О.А. Вегетативнососудистые пароксизмы. М.: Медицина, 1971, $156 \mathrm{c}$.

6. Вейн А.М., Соловьева А.Д. Лимбикоретикулярный комплекс и вегетативная регуляция. Л.: Наука, 1973, 268 с.

7. Вейн А.М. Вегетативные расстройства. МИА. Москва -1998, 746с.

8. Вейн А.М. Вегетативные расстройства: Клиника, диагностика, лечение. М.: Мединформагенство, 2000, 752 с.

9. Дюкова Г.M. Клиникоэкспериментальное исследование Вегета $\neg$ тивной нервной системы при неврозах: Дис. ..канд. мед. наук, М., 1977, 156 с.

10. Захаров А.И. Психологические факторы формирования неврозов у детей и подростков: 
Автореф. дис...докт. психол. наук. Л., 1991, 46 c.

11. Захарова Н.Н., Авдеев В.М. Функциональные изменения ЦНС при восприятии музыки // Журн. высш. неврн. деят., 1982, м.32, №5, с. 915-919.

12. Корабельникова Е.А., Голубев В.Л. Сновидения и психологическая защита при невротических расстройствах у детей и подростков. // Журн. неврол. психиатр., 2000, №1, c.18-22.

13. Колосова О.А. Роль особенностей личности в формировании психовегетативных нарушений. В кн.: «Вегетативные расстройства». М.: Мединформагенство, 2000, c. $463-470$.

14. Логунова Г.И. Психофизиологические особенности эмоциональной реактивности у детей 3-7 лет: Автореф. дис.... канд. биол. наук, M., 1977, 22c.

15. Сирота Т.И. Изменения сердечного ритма при дозированной умственной нагрузке. Новые исследования по возрастной физиологии // Педагогика, М., АПН СССР, 1980, № 2(15), с. $39-43$.

16. Соколова Л.В. Специфика спектральных характеристик ЭЭГ детей с трудностями при обучении чтению // Физиология человека, 1991, т.17, №5, с.125-129.

17. Соловьева А.Д., Филатова Е.Г., Аверкина Н.А. Лечение вегетативных расстройств препаратом ксанаксом // Журн. неврол. и психиатр., 2000, №1, с.28-32.

18. Воробьева О.В., Ханаев Б.А. Суточный амбулаторный мониторинкардиоваскулярных показателей у больных паническими расстройствами. // Журн. неврол. и психиатр., 2000, №1, c.33-37.

19. Walter W.G. The living brain. London, Duck-worth, 1957, 216 p.

\section{XÜLASə}

\section{SAKITT VӘZIYYYӘTDə Və MÜXTӘLIFF EMOSIOGEN TOSİRLOR NOTICOSINDO SəRHӘD POZĞUNLUQLARI OLAN 15-18 YAŞLI GONCLORIN VEGETATIV GÖSTORICIILORI}

\footnotetext{
${ }^{1}$ A.H.Kazımov, ${ }^{1}$ A.M.Məmmədov, ${ }^{1}$ D.M.Oliyeva,
}

${ }^{2} X . \dot{I} . H ə s ə n o v$

${ }^{1}$ Azərbaycan Tibb Universiteti, normal fiziologiya kafedras1, Bak1;

${ }^{2}$ Akad. Mir-Qasımov adına Respublika klinik xəstaxanas1, Bak1

Tədqiqatlar 15-18 yaşlı gənclərin müxtəlif funnksional vəziyyətlərdə vegetativ sfera, sinxronizə və desinxronizə edici sistemlərdə baş verən dəyişikliklərin öyrənilməsinə həsr olunmuşdur. Müəyyən olunmuşdur ki yaş göstəricilərin inkişafi və vegetativ funksiyalarin dinamikası obyektiv fərdi-tipoloji göstəricilər olduğu bir halda kardio-respirator parametrlər və emosional-vegetativ reaktivliyin dəyişiklikləri ilə fərqlənir. Fizioloji sakitlik şəraitində 15-16 yaşlı gənclərdə kardio-respirator və emosional-vegetativ göstəricilərin yüksək dəyişkənliyi aşkar edilir. Açar sözlər: yeniyetmə dövrü, vegetativ sinir sistemi, emosional vəziyyət, vegetativ sinaqlar.

\section{SUMMARY}

VEGETATIVE SPHERE OF THE 15-18 YEARS OLD YOUNG MEN SUFFERING FROM FRONTIER DISTURBANSES INN A QUIET CONDITIOON AND AT VARİOUS EMOTIOGENEOUS İNFLUENCES

\section{${ }^{1}$ A.Q.Kazimov, ${ }^{1}$ A.M. Mamedov, ${ }^{1}$ D.M. Aliyeva, ${ }^{2}$ X.İ.Hasanov}

${ }^{1}$ Department of Normal Physiology of Azerbaijan Medical University, Baku;

${ }^{2}$ Republican clinical hospital named after Acad. Mir-Gasimov, Baku

The work is devoted to study of a condition of synchronizing and desynchronizing systems, of vegetative sphere at various functional conditions of a brain at the young men of $15-18$ years old. It is revealed, that the age characteristics of development and dynamics of vegetative functions are objective individual - typological parameters and differ on cardio-respiratory parameters of functions and changes emotional-vegetative reactivity. In conditions of physiological rest the cardiorespiratory and emotional-vegetative parameters at the young men of 15-16 years old find out a high variability of absolute meanings of functions (heart beats, rate of breathing, arterial pressure).

Key words: adolescence, autonomic nervous system, emotional state, autonomic tests. 